\title{
Herpesvírus bovino tipo 1 (BoHV-1): método de diagnóstico e sua influência na qualidade espermática em touros infectados experimentalmente
}

\author{
[Bovine Herpes virus type 1 (BoHV-1): Diagnosis method and its influence on spermatic \\ quality in experimentally infected bulls]
W.J. Souza ${ }^{1}$, E.P. Nascente ${ }^{1}$, F.C. Santos ${ }^{1}$, J.V. Malaquias $^{2}$, J.R.B. Sereno ${ }^{2}$, E.F. Viana ${ }^{1}$, C.G. Silva ${ }^{3}$, C.F. Martins ${ }^{2}$ \\ ${ }^{1}$ Instituto Federal de Educação, Ciência e Tecnologia Goiano - Urutaí, Goiás, Brasil \\ ${ }^{2}$ Embrapa Cerrados - Brasília, Distrito Federal, Brasil \\ ${ }^{3}$ Centro Universitário de Desenvolvimento do Centro-Oeste, Luziânia, Goiás, Brasil
}

\begin{abstract}
RESUMO
O herpesvírus bovino tipo-1 (BoHV-1) é um vírus amplamente distribuído no Brasil e no mundo, havendo um crescente número de estudos envolvendo métodos de diagnóstico e o seu impacto na reprodução animal. O objetivo deste trabalho foi identificar o material genético do BoHV-1 no sêmen de touros infectados experimentalmente por meio da técnica de PCR e avaliar a influência do vírus sobre a qualidade espermática desses animais. A técnica de PCR foi satisfatória, permitindo identificar a presença do material genético do vírus no sêmen de todos os animais a partir de sete dias pós-infecção, com persistência de 21 até 28 dias. Apesar da presença do vírus BoHV-1 por um longo período no sêmen dos animais experimentais, não foram observados efeitos deletérios na qualidade do sêmen fresco e nem após a criopreservação.
\end{abstract}

Palavras-chave: BoHV-1, pecuária, reprodução animal, virologia

\begin{abstract}
Bovine Herpesvirus type-1 (BoHV-1) is a virus widely distributed in Brazil and worldwide, with a growing number of studies involving diagnostic methods and their impact on animal reproduction. The objective of this work was to identify the genetic material of BoHV-1 in the semen of experimentally infected bulls through the PCR technique, and to evaluate the influence of the virus on the sperm quality of these animals. The PCR technique was satisfactory, allowing for the identification of the presence of the genetic material of the virus in the semen of all the animals from 7 days post infection, with persistence of 21 to 28 days. Despite the presence of the BoHV-1 virus over a long period in the semen of the experimental animals, no deleterious effects were observed on the quality of either fresh semen or semen after the cryopreservation.
\end{abstract}

Keywords: BoHV-1, livestock, animal reproduction, virology

\section{INTRODUÇÃO}

O herpesvírus bovino tipo 1 (BoHV-1) é um vírus de distribuição mundial (Van, 1998), com elevada frequência no rebanho brasileiro, causando grandes perdas econômicas. Estudos têm sido realizados nas diferentes regiões brasileiras, principalmente na região Sudeste e, recentemente, no Centro-Oeste, onde o diagnóstico e o impacto desse agente na reprodução animal têm sido alvo dos pesquisadores (Gatti et al., 2010).

Recebido em 7 de agosto de 2017

Aceito em 6 de setembro de 2017

E-mail: wesleyjs16@hotmail.com
A transmissão desse vírus tem sido amplamente favorecida pelo desenvolvimento de processos de criopreservação do sêmen, uma vez que essas técnicas de processamento e armazenamento são ideais para a preservação desse agente (Rocha, 1999). A presença do BoHV-1 no sêmen implica o risco potencial de disseminação desse agente entre os rebanhos de todo o mundo, implicações essas que se centram na infeç̧ão exclusiva da fêmea receptora, do coletivo da exploração pecuária e também na possível introdução dessa virose no país importador (Philipott, 1993). 
Devido às limitações de algumas técnicas de diagnóstico, têm-se adotado técnicas simples e de fácil execução para a caracterização de proteínas e ácidos nucleicos por meio da reação em cadeia da polimerase (PCR), sendo recomendadas para substituir os métodos convencionais de diagnóstico desse vírus (Rodrigues e Schudel, 1993). Estudos que correlacionem a infecção pelo BoHV-1 em touros com possíveis alterações na espermatogênese dos animais infectados ainda são muitos escassos, havendo também a necessidade de novas pesquisas para ampliar conhecimentos sobre o diagnóstico.

O objetivo deste trabalho foi identificar o material genético do BoHV-1 no sêmen de animais submetidos à infecção experimental por meio da PCR, a fim de identificar a influência do vírus sobre os parâmetros que determinam a qualidade espermática de touros.

\section{MATERIAL E MÉTODOS}

Este experimento foi autorizado pelo Ceua Comissão de Ética no Uso de Animais da Universidade Estadual Paulista "Júlio de Mesquita Filho”, campus de Jaboticabal, com protocolo de número 0143030/11. Foram utilizados 12 bovinos machos, mestiços Girolandos, não castrados, com aproximadamente 30 meses de idade, com suas características espermáticas dentro dos padrões exigidos. Os animais foram criados com o mesmo manejo, em locais diferentes da mesma propriedade (Fazenda Palmital) do Instituto Federal Goiano, campus Urutaí - Goiás. Os touros foram separados em dois grupos, com seis animais cada, mantidos em locais diferentes. Um grupo foi utilizado como controle, e outro composto por animais inoculados experimentalmente com o BoHV-1.

Para a infecção experimental, foi utilizada a amostra padrão Nebraska do BoHV-1, inoculada pelas vias intranasal, intraprepucial e intratesticular, com $5 \mathrm{~mL}$ de suspensão viral (dose total de $10^{7,0} \mathrm{TCID}_{50} / \mathrm{mL}$ ), em todas as vias. Após a inoculação, os animais apresentaram alterações clínicas características, como hipertermia, edema e hiperemia prepucial, vesículas no prepúcio, pústulas na mucosa peniana, úlceras e área hiperêmica na mucosa prepucial, como demonstrado previamente
(Souza et al., 2013). Foram realizadas oito coletas de sêmen em cada grupo de touros controle e inoculados, com intervalos semanais, sendo a primeira feita antes, no dia zero, e as demais nos dias sete, 14, 21, 28, 35, 42 e 49 após a inoculação experimental. Ao todo, foram coletadas 96 amostras de sangue e 96 de sêmen em ambos os grupos, durante todo 0 experimento. A coleta de sêmen foi realizada por meio de eletroejaculação, e todas as coletas realizadas seguiram o protocolo preconizado por (Silva e Dode, 1993).

As avaliações dos sêmens fresco e criopreservado foram realizadas segundo as recomendações do Colégio Brasileiro de Reprodução Animal (Manual..., 2013). A motilidade e o vigor dos espermatozoides foram analisados sobre lâmina aquecida à temperatura de $37^{\circ} \mathrm{C}$, em microscópio de contraste de fase com aumento de $100 \mathrm{x}$. O resultado da motilidade foi dado em valores de $0 \%$ a $100 \%$. O vigor foi avaliado em uma escala de 0 a 5 , classificando, dessa forma, a diferença de intensidade de movimento dos espermatozoides. O volume foi averiguado pela leitura direta do tubo de coleta, graduado com fração de $0,1 \mathrm{~mL}$.

Para a avaliação da morfologia espermática, as amostras foram mantidas em solução formolsalina tamponada. Para a realização desse teste, colocou-se uma gota de sêmen da amostra entre lâmina e lamínula, a qual foi observada em microscopia de contraste de fase, com aumento de $1.000 x$. Foram realizadas duas preparações e em cada uma foram examinadas pelo menos 100 células, perfazendo um total de 200 células analisadas para cada amostra. Os resultados de frequências das alterações foram expressos em porcentagem, sendo detectadas a quantidade de espermatozoides normais e a ocorrência de possíveis defeitos espermáticos. Posteriormente, os defeitos foram classificados, de acordo com Blom (1973).

Após a motilidade, o vigor e o volume terem sido averiguados, o ejaculado foi diluído com o meio de congelamento Botu-Bov (BotupharmaLtda./ME), na proporção de 1:1, e mantido à temperatura de $37^{\circ} \mathrm{C}$ até o término do cálculo da concentração espermática (CBRA, 2013) e, consequentemente, até a definição do volume final do diluente. Cerca de $30 \times 10^{6}$ espermatozoides foram alocados por palheta de $0,5 \mathrm{~mL}$, todas elas 
identificadas previamente. As palhetas foram criopreservadas utilizando-se um equipamento automatizado (TK-3000 Modular SE, Brasil) com curva de resfriamento controlada. As amostras foram submetidas a uma redução de temperatura de $0,25^{\circ} \mathrm{C} / \mathrm{min}$ até $5^{\circ} \mathrm{C}$, permanecendo nessa temperatura por duas horas. A temperatura foi reduzida a $20^{\circ} \mathrm{C} / \mathrm{min}$ até atingir $-120^{\circ} \mathrm{C}$, e finalmente elas foram imersas em nitrogênio líquido. As palhetas foram descongeladas em banho-maria, a $37^{\circ} \mathrm{C}$, por 30 minutos. A amostra foi homogeneizada, e a motilidade, o vigor e a morfologia espermática foram avaliados novamente.

Para se avaliarem os danos da criopreservação associado à presença do vírus, utilizaram-se sondas fluorescentes para avaliação estrutural de membrana plasmática e acrossoma. A integridade da membrana plasmática foi avaliada por meio do uso do acetado de carboxifluoresceína (C-FDA), em associação com o iodeto de propídeo (IP) (Molecular Probe ${ }^{\circledR}$, Eugene, Oregon, EUA), como descrito por Martins et al. (2011). Foram examinadas 200 células espermáticas por lâmina, sendo classificadas as porcentagens de: membrana íntegra (presença de coloração verde na cabeça) e membrana lesada (presença de coloração vermelha na cabeça) (Silva e Gadella, 2006).

A integridade do acrossoma foi avaliada utilizando-se FITC conjugado com lecitina de amendoim PNA e IP (Celeghini et al., 2008). Foram examinadas 200 células espermáticas em microscópio de contraste de fase e microscópio de epifluorescência (Axiophot Zeiss: filtro de comprimento de onda 494/517 excitação/emissão). Os espermatozoides foram classificados em quatro categorias: porcentagem de morto com acrossoma íntegro, porcentagem de morto com acrossoma reagido, porcentagem de vivo com acrossoma íntegro, porcentagem de vivo com acrossoma reagido (Celeghini et al., 2008).

Para a realização da técnica de PCR, foi utilizado o kit comercial da Prômega, em que, a partir da amplificação do DNA viral, os espermatozoides foram analisados por meio de eletroforese em gel de agarose a 2,0\%. A visualização dos fragmentos amplificados foi feita mediante transiluminação do gel em luz ultravioleta, após este ser corado em solução de brometo de etídio $(0,5 \mu \mathrm{g} / \mathrm{mL})$. O delineamento experimental foi realizado com seis repetições, no esquema fatorial 2x8, originando 16 tratamentos e totalizando 96 observações. A análise teve dois fatores: inoculação e dias após inoculação. O fator "Inoculação" foi composto pelos tratamentos: $\mathrm{C}$ - controle e I - inoculado. O fator "Dias após inoculação" foi composto por: D1 dia zero, D2 - sétimo dia, D3 - $14^{\circ}$ dia, D4 - $21^{\circ}$ dia, D5 - $28^{\circ}$ dia, D6 - $35^{\circ}$ dia, D7 - 42 ${ }^{\circ}$ dia e D8 - 49 $9^{\circ}$ dia. A verificação estatística da significância dos tratamentos será feita pela análise de variância (ANOVA) GLM. Para a comparação das médias, será utilizado o teste de Tukey, com 5\% de probabilidade. Todas as análises serão realizadas pelo software estatístico SAS, versão 9.1.2 (SAS, 2009).

\section{RESULTADOS E DISCUSSÃO}

A análise pela técnica de PCR resultou na amplificação de produtos com 160pb em 20 amostras provenientes das coletas de sêmen realizadas com intervalo de sete dias nos touros inoculados com o BoHV-1. A Fig. 1 apresenta a comprovação do DNA após a inoculação viral. Em todos os touros infectados, foi constatado material genético do BoHV-1. Em seis touros inoculados, detectou-se o DNA viral aos sete, 14 e 21 dias após inoculação do vírus. Em dois animais, foi possível identificar o vírus por um período de 28 dias, o que permitiu inferir que, nesses casos, os níveis de anticorpos provavelmente estejam mais elevados, visto que o vírus levou um maior período para entrar em estado de latência. Esses achados demonstram que a técnica de PCR é um método eficaz e rápido, constituindo um exame de eleição para detecção do vírus BoHV-1 no sêmen ou em outros fluidos corporais. Além disso, tais resultados indicam uma longa permanência do vírus no sêmen, podendo este ser transmitido pela monta natural por esse período ou via sêmen congelado.

Smiths e colaboradores (2000), ao avaliarem três técnicas diferentes de PCR, identificaram o DNA do vírus em amostras de sêmen entre o primeiro e o $44^{\circ}$ dia após a infecção, resultado que demonstra a eficácia da técnica para o diagnóstico do BoHV1 em amostras de sêmen de touros com infecção recente. Rocha et al. (1998) e Silva (2009), pelos resultados obtidos nas respectivas pesquisas, demonstraram que a técnica de PCR tem a capacidade de identificar o DNA do BoHV-1 em diferentes tipos de amostras. Alegre e colaboradores (2001), ao utilizarem a técnica PCR 
multiplex, detectaram o DNA viral em amostras de sêmen de animais inoculados pela via intranasal. Já Chandranaik (2010) detectou o material genético do vírus em amostras de sêmen provenientes de centrais de coletas de sêmen, por meio da técnica de PCR em tempo real. Em contrapartida, Oliveira et al. (2011) detectaram o DNA em amostras de sêmen provenientes de touros que não apresentavam sinais clínicos de infecção por esse vírus, utilizando a técnica do tipo nested (nPCRs).
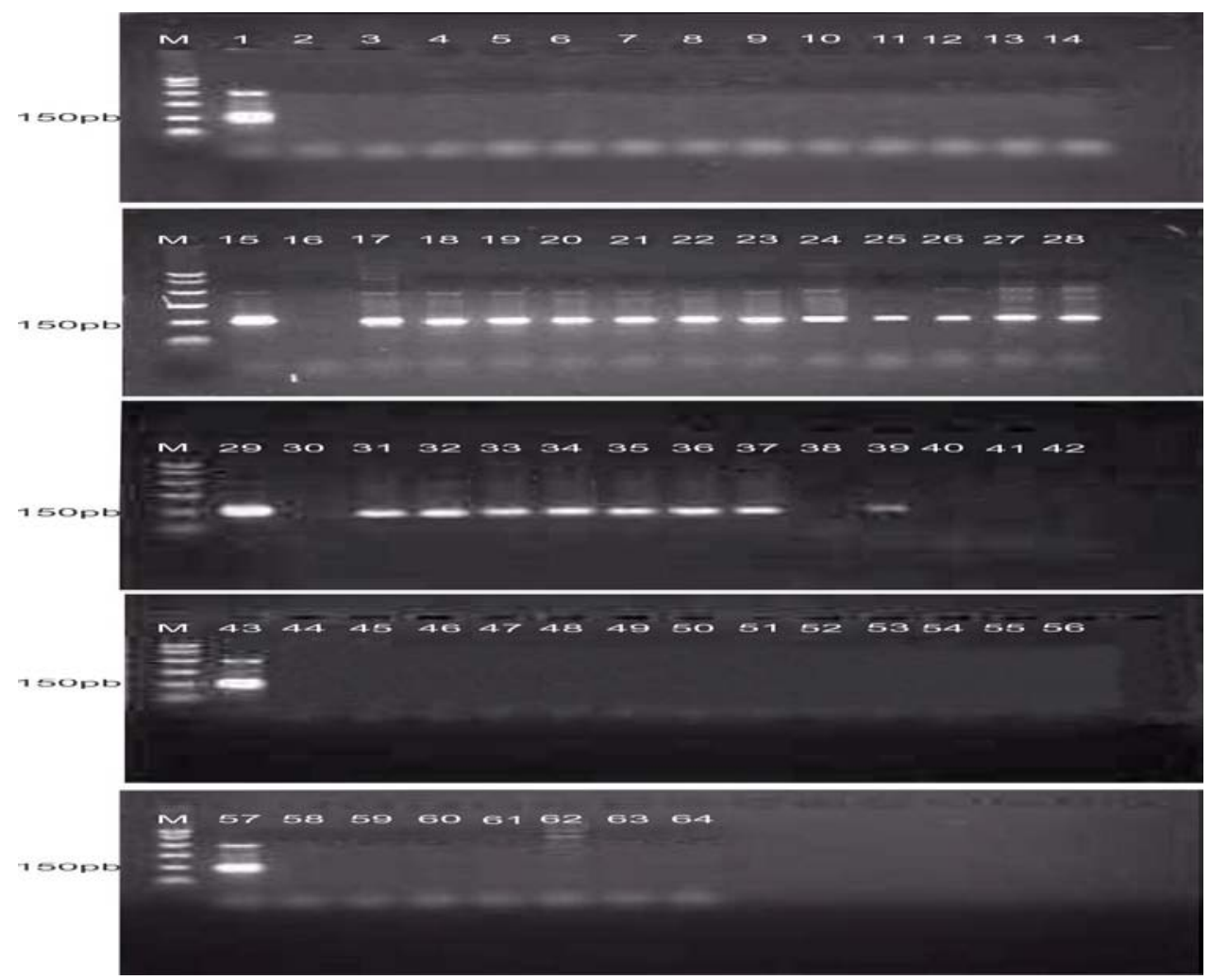

Figura 1. Comprovação do DNA por meio da técnica de PCR após a inoculação viral nos animais. Nas canaletas M, tem-se o DNA “ladder” Promega ${ }^{\circledR}$. Observam-se as canaletas dos grupos controle positivo $(1,15,29,43$ e 57$)$ e as canaletas dos controle negativo Promega ${ }^{\circledR}(2,16,30,44$ e 58). Nas canaletas de 3 a 8, encontram-se amostras dos animais do grupo controle, e nas canaletas de 9 a 14, amostras dos animais infectados coletadas no dia zero, antes da inoculação do grupo com o vírus. Canaletas de 17 a 22 contêm amostras coletadas sete dias após a inoculação do vírus; canaletas de 23 a 28 têm amostras coletadas 14 dias após a inoculação; canaletas de 31 a 36 têm amostras coletadas 21 dias após a inoculação; nas canaletas de 37 a 42, há amostras coletadas 28 dias após a inoculação dos animais; canaletas 45 a 50 referem-se às amostras coletadas 35 dias após a inoculação; canaletas de 51 a 56 são de amostras coletadas 42 dias após a inoculação, e as canaletas de 59 a 64 são de amostras coletadas 49 dias após a inoculação.

No presente estudo, o vírus foi incialmente detectado a partir do sétimo dia de infecção, período considerado precoce para um diagnóstico. Mars et al. (1996) também observaram que a técnica de PCR foi capaz de detectar o BoHV-1 precocemente, a partir do quarto dia pós-infecção, antes mesmo do aparecimento de anticorpos detectáveis pelos procedimentos sorológicos tradicionais. Mais recentemente, a PCR ganhou um diferencial com o método de diagnóstico real-time, inovação tecnológica que otimiza os resultados da técnica já existente (Chandranaik, 2010).

Os valores médios de volume de sêmen e a concentração espermática observados in natura nos touros dos grupos controle e inoculados com o BoHV-1 estão dispostos na Tab. 1. Os 
resultados das médias de volumes e concentrações espermáticas encontradas nos dois grupos se alternaram entre aumentos e diminuições, conforme o dia de coleta, porém sem indicação da influência do BoHV-1, mesmo tendo sido detectado material genético viral no sêmen dos touros inoculados nas primeiras semanas deste experimento.

Tabela 1. Média \pm desvio-padrão do volume (mL) e concentração espermática no sêmen fresco do grupo de touros controle (C) e inoculados (I) com o BoHV-1

\begin{tabular}{|c|c|c|c|c|}
\hline \multicolumn{5}{|c|}{ Parâmetros de volume e concentração espermática avaliados } \\
\hline & \multicolumn{2}{|c|}{ Volume espermático (mL) } & \multicolumn{2}{|c|}{ Concentração de espermatozoides $\left(10^{6} \mathrm{sptz} / \mathrm{mL}\right)$} \\
\hline & Grupo C & Grupo I & Grupo C & Grupo I \\
\hline $\mathrm{D}-0$ & $5,23 \pm 0,27 \mathrm{Aa}^{*}$ & $4,91 \pm 0,53 \mathrm{Aa}$ & $496,33 \pm 22,31 \mathrm{Aa}$ & $513,00 \pm 26,34 \mathrm{Aa}$ \\
\hline $\mathrm{D}-7$ & $5,15 \pm 0,42 \mathrm{Aa}$ & $5,40 \pm 0,20 \mathrm{Aa}$ & $507,50 \pm 42,27 \mathrm{Aa}$ & $519,00 \pm 26,68 \mathrm{Aa}$ \\
\hline D-14 & $5,58 \pm 0,31 \mathrm{Aa}$ & $5,21 \pm 0,42 \mathrm{Aa}$ & $494,50 \pm 35,85 \mathrm{Aa}$ & $523,83 \pm 24,84 \mathrm{Aa}$ \\
\hline D-21 & $4,98 \pm 0,54 \mathrm{Aa}$ & $5,30 \pm 0,35 \mathrm{Aa}$ & $518,66 \pm 22,70 \mathrm{Aa}$ & $504,66 \pm 24,51 \mathrm{Aa}$ \\
\hline D-28 & $5,43 \pm 0,22 \mathrm{Aa}$ & $4,93 \pm 0,51 \mathrm{Aa}$ & $503,50 \pm 24,96 \mathrm{Aa}$ & $524,50 \pm 16,30 \mathrm{Aa}$ \\
\hline D-35 & $5,13 \pm 0,44 \mathrm{Aa}$ & $5,35 \pm 0,23 \mathrm{Aa}$ & $515,50 \pm 18,51 \mathrm{Aa}$ & $497,50 \pm 12,16 \mathrm{Aa}$ \\
\hline D-42 & $5,28 \pm 0,25 \mathrm{Aa}$ & $5,01 \pm 0,45 \mathrm{Aa}$ & $489,50 \pm 32,41 \mathrm{Aa}$ & $517,33 \pm 19,69 \mathrm{Aa}$ \\
\hline D-49 & $5,46 \pm 0,19$ Aа & $5,33 \pm 0,30 \mathrm{Aa}$ & $501,33 \pm 19,31 \mathrm{Aa}$ & $520,16 \pm 33,70 \mathrm{Aa}$ \\
\hline
\end{tabular}

*Nas colunas, letras maiúsculas iguais indicam semelhança estatística $(\mathrm{P} \geq 0,05)$, e, nas linhas, letras minúsculas iguais indicam semelhança estatística ( $\mathrm{P} \geq 0,05)$, para cada parâmetro avaliado.

Neste estudo, não foi observada a influência negativa do vírus sobre a produção de espermatozoides em bovinos. Não existem dados na literatura correlacionando a presença BoHV-1 no sêmen com a diminuição da concentração espermática. No entanto, Paton et al. (1989), ao avaliarem o vírus da diarreia viral bovina (BVDV), observaram redução nas médias de concentração espermática, entretanto nesse estudo os volumes seminais não foram relatados. Em contrapartida, Sekoni et al. (2004) analisaram os mesmos parâmetros em animais infectados com Trypanossoma vivax e concluíram que as reduções das concentrações e dos volumes espermáticos foram influenciadas pela ação do $T$. vivax detectado no sangue dos touros após a infecção experimental.

Os resultados referentes à porcentagem de motilidade e vigor das células espermáticas dos grupos experimentais estão apresentados nas Tab. 2 e 3. Não houve diferença estatística $(\mathrm{P} \geq 0,05)$ para as médias de motilidade e vigor encontradas entre os animais do grupo controle e inoculados, nem para os tratamentos antes do congelamento e após o descongelamento, no sêmen fresco ou mesmo congelado.

Os resultados de motilidade espermática e vigor detectados antes e após a descongelação do sêmen no grupo de touros inoculados não foram afetados pela presença do BoHV-1. Esses resultados corroboram os observados de Souza et al. (2011), que, ao avaliarem amostras de sêmen de touros infectados com o herpesvírus bovino tipo 5, observaram que não houve alterações na motilidade espermática. Já Alm (2009) detectou possível interferência nos percentuais de motilidade espermática, que variaram entre $40 \%$ e $60 \%$ nas amostras de sêmen de 54 touros infectados naturalmente pelo vírus respiratório sincicial bovino (BRSV).

Resultados semelhantes a este trabalho foram encontrados para o parâmetro de vigor espermático, mas com outro patógeno. Segundo Galvão (2009), a infestação pela Dermatobia hominis não interfere nos valores de vigor espermático detectados durante o experimento. Já Buzunhani et al. (2011) detectaram redução nos valores médios de vigor espermático em touros infectados experimentalmente com Ureaplasma diversum.

Os resultados percentuais de defeitos maiores, menores e totais dos grupos de touros controle e inoculados estão dispostos na Tab. 4. Novamente, ao ser realizada uma análise comparativa das médias de todos os grupos, para as três características estudadas, os resultados foram estatisticamente semelhantes ( $\underline{\underline{P}}$ 0,05). A presença do vírus nos animais inoculados não gerou danos à espermatogênese nem à maturação espermática no epidídimo e, consequentemente, não interferiu na morfologia espermática. 
Tabela 2. Média \pm desvio-padrão das porcentagens de motilidade de espermatozoides no sêmen fresco e pós-descongelamento proveniente do grupo de touros controle (C) e inoculados (I) com o BoHV-1

\begin{tabular}{|c|c|c|c|c|}
\hline \multicolumn{5}{|c|}{ Parâmetros de motilidade de espermatozoides avaliados em (\%) } \\
\hline \multicolumn{3}{|c|}{ Antes congelamento } & \multicolumn{2}{|c|}{ Pós-descongelamento } \\
\hline & $\mathrm{C}$ & $\mathrm{I}$ & $\mathrm{C}$ & $\mathrm{I}$ \\
\hline $\mathrm{D}-0$ & $71,66 \pm 4,08 \mathrm{Aa}^{*}$ & $73,33 \pm 5,16$ Aa & $38,33 \pm 6,32 \mathrm{Aa}$ & $43,33 \pm 8,16 \mathrm{Aa}$ \\
\hline $\mathrm{D}-7$ & $73,33 \pm 5,16 \mathrm{Aa}$ & $76,66 \pm 5,16$ Aa & $40,00 \pm 7,83 \mathrm{Aa}$ & $46,66 \pm 5,16$ Aa \\
\hline D-14 & $78,33 \pm 4,08 \mathrm{Aa}$ & $75,00 \pm 5,47 \mathrm{Aa}$ & $45,00 \pm 5,47 \mathrm{Aa}$ & $43,33 \pm 5,16$ Aa \\
\hline $\mathrm{D}-21$ & $75,00 \pm 5,47 \mathrm{Aa}$ & $76,66 \pm 5,16$ Aa & $41,66 \pm 7,52 \mathrm{Aa}$ & $45,00 \pm 5,47 \mathrm{Aa}$ \\
\hline $\mathrm{D}-28$ & $76,66 \pm 5,16$ Aa & $73,33 \pm 5,16$ Aa & $43,33 \pm 8,16 \mathrm{Aa}$ & $40,00 \pm 7,52 \mathrm{Aa}$ \\
\hline D-35 & $70,00 \pm 6,32 \mathrm{Aa}$ & $75,00 \pm 5,47 \mathrm{Aa}$ & $38,33 \pm 7,52 \mathrm{Aa}$ & $41,66 \pm 6,32 \mathrm{Aa}$ \\
\hline D-42 & $75,00 \pm 5,47 \mathrm{Aa}$ & $71,66 \pm 4,08 \mathrm{Aa}$ & $40,00 \pm 8,16 \mathrm{Aa}$ & $45,00 \pm 5,47 \mathrm{Aa}$ \\
\hline D-49 & $73,33 \pm 8,16 \mathrm{Aa}$ & $75,00 \pm 5,47 \mathrm{Aa}$ & $43,33 \pm 6,32 \mathrm{Aa}$ & $46,66 \pm 5,16 \mathrm{Aa}$ \\
\hline
\end{tabular}

*Nas colunas, letras maiúsculas iguais indicam semelhança estatística $(\mathrm{P} \geq 0,05)$, e, nas linhas, letras minúsculas iguais indicam semelhança estatística $(\mathrm{P} \geq 0,05)$, para cada parâmetro avaliado.

Tabela 3. Médias \pm desvio-padrão da escala ( 0 a 5) de vigor de espermatozoides no sêmen fresco e pósdescongelamento proveniente dos grupos de touros controle (C) e inoculados (I) com o BoHV-1

Parâmetros de vigor de espermatozoides avaliados

\begin{tabular}{ccccc}
\hline \multicolumn{2}{c}{ Antes congelamento } & \multicolumn{2}{c}{ Pós-descongelamento } \\
\hline & C & I & C & I \\
\hline D-0 & $3,66 \pm 0,51 \mathrm{Aa} *$ & $3,50 \pm 0,54 \mathrm{Aa}$ & $2,66 \pm 0,51 \mathrm{Aa}$ & $2,83 \pm 0,40 \mathrm{Aa}$ \\
D-7 & $3,33 \pm 0,51 \mathrm{Aa}$ & $3,66 \pm 0,51 \mathrm{Aa}$ & $2,50 \pm 0,54 \mathrm{Aa}$ & $2,83 \pm 0,40 \mathrm{Aa}$ \\
D-14 & $3,83 \pm 0,40 \mathrm{Aa}$ & $3,33 \pm 0,51 \mathrm{Aa}$ & $3,00 \pm 0,00 \mathrm{Aa}$ & $2,66 \pm 0,51 \mathrm{Aa}$ \\
D-21 & $3,83 \pm 0,40 \mathrm{Aa}$ & $3,83 \pm 0,40 \mathrm{Aa}$ & $2,83 \pm 0,40 \mathrm{Aa}$ & $3,00 \pm 0,00 \mathrm{Aa}$ \\
D-28 & $3,33 \pm 0,51 \mathrm{Aa}$ & $3,50 \pm 0,54 \mathrm{Aa}$ & $2,66 \pm 0,51 \mathrm{Aa}$ & $3,00 \pm 0,00 \mathrm{Aa}$ \\
D-35 & $3,50 \pm 0,54 \mathrm{Aa}$ & $3,83 \pm 0,40 \mathrm{Aa}$ & $3,00 \pm 0,00 \mathrm{Aa}$ & $2,66 \pm 0,51 \mathrm{Aa}$ \\
D-42 & $3,83 \pm 0,40 \mathrm{Aa}$ & $3,66 \pm 0,51 \mathrm{Aa}$ & $2,83 \pm 0,40 \mathrm{Aa}$ & $3,00 \pm 0,00 \mathrm{Aa}$ \\
D-49 & $3,50 \pm 0,54 \mathrm{Aa}$ & $3,66 \pm 0,51 \mathrm{Aa}$ & $2,50 \pm 0,54 \mathrm{Aa}$ & $2,83 \pm 0,40 \mathrm{Aa}$ \\
\hline
\end{tabular}

*Nas colunas, letras maiúsculas iguais indicam semelhança estatística $(\mathrm{P} \geq 0,05)$, e, nas linhas, letras minúsculas iguais indicam semelhança estatística ( $\mathrm{P} \geq 0,05)$, para cada parâmetro avaliado.

Tabela 4. Médias \pm desvio-padrão das porcentagens de defeitos maiores, defeitos menores e totais de espermatozoides do grupo de touros controle (C) e inoculados (I) com o BoHV-1

\begin{tabular}{|c|c|c|c|c|c|c|}
\hline \multicolumn{7}{|c|}{ Parâmetros de defeitos espermáticos avaliados em (\%) } \\
\hline & \multicolumn{2}{|c|}{ Defeitos maiores } & \multicolumn{2}{|c|}{ Defeitos menores } & \multicolumn{2}{|c|}{ Defeitos totais } \\
\hline & $\mathrm{C}$ & $\mathrm{I}$ & $\mathrm{C}$ & I & $\mathrm{C}$ & $\mathrm{I}$ \\
\hline $\mathrm{D}-0$ & $11,25 \pm 1,50 \mathrm{Aa}$ & $10,41 \pm 2,06 \mathrm{Aa}$ & $8,00 \pm 1,26 \mathrm{Aa}$ & $8,50 \pm 1,44 \mathrm{Aa}$ & $19,25 \pm 1,47 \mathrm{Aa}$ & $18,91 \pm 1,82 \mathrm{Aa}$ \\
\hline D-7 & $10,50 \pm 1,54 \mathrm{Aa}$ & $11,33 \pm 1,32 \mathrm{Aa}$ & 7,50 $\pm 1,18 \mathrm{Aa}$ & $7,67 \pm 1,16$ Aa & $18,00 \pm 1,44 \mathrm{Aa}$ & $19,00 \pm 1,24 \mathrm{Aa}$ \\
\hline D-14 & $12,75 \pm 1,03 \mathrm{Aa}$ & $11,00 \pm 1,81 \mathrm{Aa}$ & $7,33 \pm 1,21 \mathrm{Aa}$ & $7,83 \pm 1,47 \mathrm{Aa}$ & $20,08 \pm 1,02 \mathrm{Aa}$ & $18,83 \pm 1,66 \mathrm{Aa}$ \\
\hline D-21 & $10,66 \pm 1,80 \mathrm{Aa}$ & $11,75 \pm 1,21 \mathrm{Aa}$ & $8,00 \pm 1,41 \mathrm{Aa}$ & $7,41 \pm 1,28 \mathrm{Aa}$ & $18,66 \pm 2,18 \mathrm{Aa}$ & 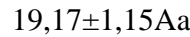 \\
\hline D-28 & $11,00 \pm 1,37 \mathrm{Aa}$ & $10,50 \pm 1,18 \mathrm{Aa}$ & $8,33 \pm 1,08 \mathrm{Aa}$ & $7,17 \pm 1,12$ Аа & $19,33 \pm 1,63 \mathrm{Aa}$ & $17,67 \pm 2,06 \mathrm{Aa}$ \\
\hline D-35 & $12,25 \pm 1,17 \mathrm{Aa}$ & $11,08 \pm 1,82 \mathrm{Aa}$ & $7,25 \pm 1,54 \mathrm{Aa}$ & $8,75 \pm 1,28 \mathrm{Aa}$ & $19,50 \pm 1,70 \mathrm{Aa}$ & $19,83 \pm 2,60 \mathrm{Aa}$ \\
\hline D-42 & $10,75 \pm 2,08 \mathrm{Aa}$ & $10,91 \pm 1,82 \mathrm{Aa}$ & 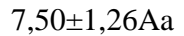 & $7,00 \pm 1,04 \mathrm{Aa}$ & $18,25 \pm 2,50 \mathrm{Aa}$ & $17,91 \pm 1,46 \mathrm{Aa}$ \\
\hline D-49 & $12,50 \pm 1,51 \mathrm{Aa}$ & $10,25 \pm 2,00 \mathrm{Aa}$ & $7,75 \pm 1,12 \mathrm{Aa}$ & $8,25 \pm 1,36 \mathrm{Aa}$ & $20,25 \pm 1,08 \mathrm{Aa}$ & $18,50 \pm 1,03 \mathrm{Aa}$ \\
\hline
\end{tabular}

*Nas colunas, letras maiúsculas iguais indicam semelhança estatística $(\mathrm{P} \geq 0,05)$, e, nas linhas, letras minúsculas iguais indicam semelhança estatística ( $\mathrm{P} \geq 0,05)$, para cada parâmetro avaliado.

Sekoni et al. (2004) observaram aumento dos defeitos espermáticos totais após inoculação experimental com Trypanossoma congolense. Alm (2009) observou aumento dos defeitos totais em touros infectados pelo vírus respiratório sincicial bovino (BRSV), enquanto Whitmore et al. (1977) e Paton et al. (1989) observaram aumento nesses percentuais após a infecção experimental de touros com o BVDV. O aumento dos defeitos espermáticos totais estão diretamente relacionados a alterações de temperatura e tropismo pelo tecido testicular, onde uma resposta inflamatória sistêmica pode desencadear degeneração testicular (Bezerra et al., 2008).

Na avaliação de integridade da membrana, os percentuais de espermatozoides com membranas íntegras constam na Tab. 5. As médias encontradas nos dois grupos tiveram resultados 
semelhantes e a análise comparativa dos grupos e dos dias de cada grupo demonstrou similaridade estatística entre os resultados encontrados $(\mathrm{P} \geq 0,05)$. Assim como para os demais parâmetros avaliados, médias percentuais de espermatozoides com membranas íntegras encontradas no grupo dos touros inoculados apresentaram resultados com pequenas variações em todo o tempo da pesquisa, indicando que a presença do vírus não trouxe prejuízo à estrutura de membrana plasmática durante o processo de criopreservação espermática. Não há dados na literatura referenciando a influência ou não do vírus BoHV1 sobre a membrana plasmática dos espermatozoides bovinos.

Tabela 5. Médias \pm desvio-padrão das porcentagens da integridade de membrana plasmática de espermatozoides do grupo de touros controle (C) e inoculados (I) com o BoHV-1

\begin{tabular}{ccc}
\hline \multicolumn{3}{c}{ Parâmetro de integridade de membrana avaliado em (\%) } \\
\hline D-0 & $\mathrm{C}$ & $\mathrm{I}$ \\
D-7 & $40,83 \pm 2,85 \mathrm{Aa}^{*}$ & $39,50 \pm 3,20 \mathrm{Aa}$ \\
D-14 & $39,83 \pm 2,71 \mathrm{Aa}$ & $42,33 \pm 3,44 \mathrm{Aa}$ \\
D-21 & $41,66 \pm 2,06 \mathrm{Aa}$ & $40,50 \pm 2,88 \mathrm{Aa}$ \\
D-28 & $39,16 \pm 2,22 \mathrm{Aa}$ & $41,16 \pm 3,18 \mathrm{Aa}$ \\
D-35 & $41,00 \pm 2,28 \mathrm{Aa}$ & $43,00 \pm 4,09 \mathrm{Aa}$ \\
D-42 & $38,83 \pm 3,54 \mathrm{Aa}$ & $40,83 \pm 2,63 \mathrm{Aa}$ \\
D-49 & $40,33 \pm 1,96 \mathrm{Aa}$ & $39,33 \pm 2,33 \mathrm{Aa}$ \\
\hline
\end{tabular}

* Nas colunas, letras maiúsculas iguais indicam semelhança estatística $(\mathrm{P} \geq 0,05)$, e, nas linhas, letras minúsculas iguais indicam semelhança estatística $(\mathrm{P} \geq 0,05)$, para o parâmetro avaliado.

A análise dos grupos e dos dias, dos grupos de touros controle e inoculados com BoHV-1, referente aos espermatozoides mortos e vivos, sem e com reação acrossomal (Tab. 6), indicou ausência de diferença estatisticamente significativa $(\mathrm{P} \geq 0,05)$ entre todos os resultados encontrados. Os percentuais médios de acrossomos íntegros detectados no sêmen do grupo de touros inoculados variaram durante todo o experimento e possivelmente não foram associados à presença do BoHV-1. Da mesma forma, Souza et al. (2011) não encontraram diferença estatística e possível interferência do BoHV-5 nos percentuais de espermatozoides vivos com reação acrossomal.

Tabela 6. Média \pm desvio-padrão das porcentagens de espermatozoides vivos, sem reação acrossomal (S/R/A) e com reação acrossomal (C/R/A), e mortos (S/R/A) e (C/R/A) do sêmen dos grupos de touros controle (C) e inoculados (I) com o BoHV-1

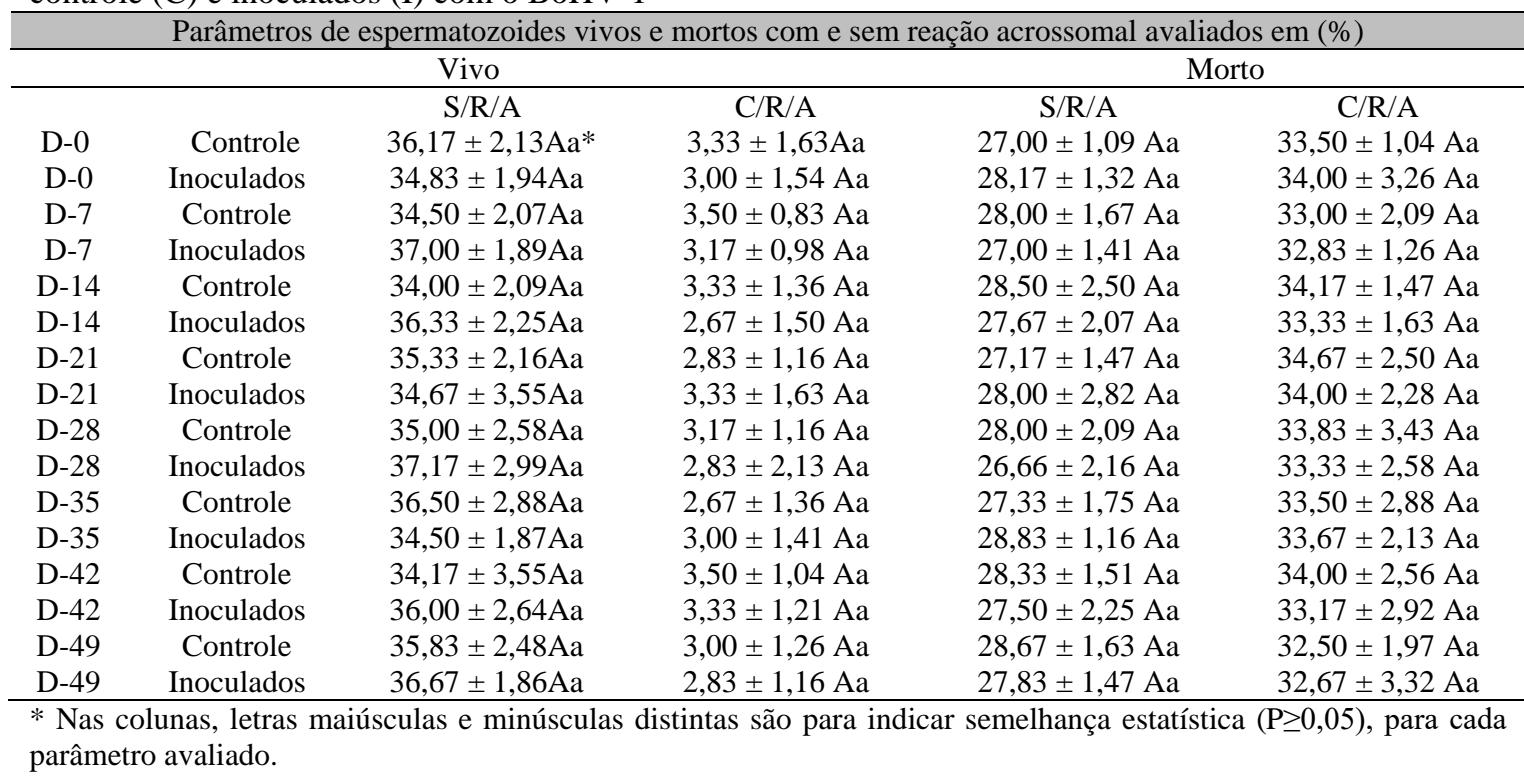




\section{CONCLUSÃO}

Foi possível identificar a presença do material genético do vírus no sêmen de todos os animais a partir de sete dias pós-infecção, com persistência de até 28 dias, sendo o método de PCR sensível e rápido para esse diagnóstico precoce desse vírus no sêmen bovino. A presença do vírus BoHV-1 não afetou a qualidade do sêmen fresco dos animais infectados, bem após a criopreservação. $\mathrm{O}$ vírus permanece no sêmen bovino por cerca de quatro semanas, podendo contaminar fêmeas por meio da monta ou sêmen congelado, sendo necessário estabelecer a PCR em centrais de inseminação artificial para se evitar a disseminação desse vírus.

\section{REFERÊNCIAS}

ALEGRE, M.; NANNI, M.; FONDEVILA, N. Development of a multiplex polymerase chain raction for the differentiation of bovine herpesvirus-1 and 5. J. Vet. Med., v.48, p.613621, 2001.

ALM, K. Semen quality and fertility after artificial insemination in dairy cattle and pigs. 2009. 52f. Dissertação (Mestrado em Medicina Veterinária) - University of Helsinki Finland, Helsinki.

BEZERRA, F.S.B.; GARCIA, H.Á.; ALVES, H.M. et al. Trypanosoma vivax nos tecidos testiculares e epididimário de ovinos experimentalmente infectados. Pesqui. Vet. Bras., v.28, p.575-582, 2008.

BLOM, E. The ultrastructure of some characteristic sperm defects and a proposal for a new classification of the bull spermogram. Nord. Vet. Med., v.25, p.383-391, 1973.

BUZUNHANI, M.; YAMAGUTI, M.; OLIVEIRA, R.O. et al. Invasion of Ureaplasma diversum in bovine spermatozoids. BMC Res. Notes, v.4, p.1-8, 2011.

CBRA, Colégio Brasileiro de Reprodução Animal. Manual para exame andrológico e avaliação de sêmen animal. 3.ed. Belo Horizonte: CBRA, 2013. 104p.

CELEGHINI, E.C.C.; ARRUDA, R.P.; ANDRADE, A.F.C. et al. Effects that bovine sperm cryopreservation using two different extenders has on sperm membranes and chromatin. Anim. Reprod. Sci., v.104, p.119-131, 2008.
CHANDRANAIK, B.M. Isolation of BHV-1 from bovine semen and application of real time PCR for diagnosis of IBR/IPV from clinical samples. Vet. Arh., v.80, p.467, 2010.

GALVÃO, A. Avaliação da aptidão reprodutiva de touros da raça Nelore, com infestação de Dermatobia hominis na bolsa escrotal. 2009. 40f. Dissertação (Mestrado em Medicina Veterinária) - Universidade Federal Rural do Rio de Janeiro, Rio de Janeiro, RJ.

GATTI, S.P.; AFFONSO. I.B.; DIAS, F.C. et al. Títulos de anticorpos anti-herpesvírus bovino tipo 1 (BoHV-1) de bezerras em três rebanhos leiteiros do estado de São Paulo, Brasil. Ars Vet., v.26, p.147-152, 2010.

MARS, S.A.; OLSON, W.; NGUYEN, P.T. et al. Rapid detection of bovine herpesvirus 1 in the semen of infected bulls by a nested polymerase chain reaction assay. Can. J. Vet. Res., v.60, p.100-107, 1996.

MARTINS, J.A.M.; SOUZA, F.A.; FERREIRA, M.B.D. et al. Desenvolvimento reprodutivo de tourinhos Gir selecionados para produção de leite. Arq. Bras. Med Vet. Zootec., v.63, p.12771286, 2011.

OLIVEIRA, M.T.; CAMPOS, F.C.; DIAS, M.M. et al. Detection of bovine herpesvírus 1 and 5 in semen from Brazilian bulls. Theriogenology, v.75, p1139-1145, 2011.

PATON, D.J.; GOODEY, R.; BROCKMAN, S. et al. Evaluation of the quality and virological status of semen from bulls acutely infected with BVDV. Vet. Rec., v.3, p.63-64. 1989.

PHILIPOTT, $M$. The dangers of disease trasmission by artificial insemination and embryo transfer. Br. Vet. J., v.149, p.339-369, 1993.

ROCHA, M.A. Diagnóstico da rinotraqueíte infecciosa bovina (IBR). Rev. Bras. Reprod. Anim., v.23 p.535-539, 1999.

ROCHA, M.A.; BARBOSA, E.F.; GUIMARÃES, S.E.F. et al. A high sensitivitynested PCR assay for BoHV-1 detection in semen of naturally infected bulls. Vet. Microbiol., v.63, p.1-11, 1998.

RODRIGUES, M.; SCHUDEL, A.A. Nucleic acid hybridisation and polymerase chain reaction in the diagnosis of infectious animal diseases. Rev. Sci. Techn., v.2, p.385-423, 1993. 
SAS Microsoft Windows, version 9.1.2. Heidelberg, Germany: SAS International. 2009.

SEKONI, V.O.; REKWOT, P.I.; BAWA, E.K. Effects of Trypanosoma vivax and Trypanosoma congolense infections on the reaction time and semen characteristics of Zebu (Bunaji) Friesian crossbred bulls. Theriogenology, v.61, p55-62, 2004.

SILVA, A.E.D.F.; DODE, M.A.N. Capacidade reprodutiva do touro de corte: funções, anormalidade e fatores que a influenciam. Campo Grande: Embrapa - CNPGC, 1993. p.78108. (Documento 51).

SILVA, M.S. Identificação molecular de herpesvírus bovino tipos 1 e 5. 2009. 69f. Tese (Doutorado em Medicina Veterinária) Universidade Federal de Santa Maria, Rio Grande do Sul, RS.

SILVA, P.F.N.; GADELLA, B.M. Detection of damage in mammalian sperm cells. Theriogenology, v.65, p.958-978, 2006.

SMITHS, C.B.; VAN, M.C.; GLAS, R.D. et al. Comparison of three polymerase chain reaction methods for routine detection of bovine herpesvirus 1 DNA in fresh buli semen. J. Virol., v.85, p.65-73, 2000.

SOUZA, D.G.; SILVA-FRADEA, C.M.; JUNIOR, A. et al. Bull semen variables after experimental exposure with bovine herpesvirus type 5. Anim. Reprod. Sci., v.124, p.55-60, 2011.

SOUZA, W.J.; SOUZA, G.S.; MEDEIROS, A.S.R. et al. Análise dos parâmetros clínicos, das alterações sorológicas e histopatológicas dos epidídimos e testículos de touros jovens infectados experimentalmente com BOHV-1. Encicl. Biosfera, v.9, p.159-168, 2013.

VAN, O.J.T. The BoHV-1 situation in Europe. In: SIMPÓSIO INTERNACIONAL SOBRE HERPESVÍRUS BOVINO (TIPOS 1 E 5) E VIRUS DA DIARRÉIA VIRAL BOVINA (BVDV), 1998, Santa Maria. Anais... Santa Maria: [s.n.], 1998. p.69-72. (Resumo).

WHITMORE, H.L.; GUSTAFSSON, B.K.; HAVARESHTI, P. et al. Inoculation of bulls whith bovine virus diarrhea virus: excretion of virus in semen and effects on semen quality. Theriogenology, v.9, p153-163, 1977. 